\title{
Thermal properties of vesicular rhyolite
}

\author{
N. Bagdassarov, D. Dingwell \\ Bayerisches Geoinstitut, Universität Bayreuth, D-95440 Bayreuth, Germany
}

(Received June 28, 1993; revised version accepted November 1, 1993)

\begin{abstract}
Thermal diffusivity of rhyolite melt and rhyolite foam (70-80\% porosity) has been measured using the radial heat transfer method. Cylindrical samples (length $\sim 50-55 \mathrm{~mm}$, diameter $\sim 22 \mathrm{~mm}$ ) of rhyolite melt and foam have been derived by heating samples of Little Glass Mountain obsidian. Using available data on heat capacity and density of rhyolite melt, the thermal conductivity of samples has been determined. The difference in thermal conductivity between rhyolite melt and foam at igneous temperatures $\left(\sim 1000^{\circ} \mathrm{C}\right)$ is about one order of magnitude. The effect of thermal insulation of magmas due to vesiculation and foaming of the top layer is discussed in terms of the data obtained using a simple illustrative model of magma chamber convection.
\end{abstract}

\section{Introduction}

Vesiculation of magmas can result in the generation of magmatic foam, a geomaterial with physical properties, such as density, viscosity and thermal conductivity, radically different from the parent magma. Natural foams play an important role in volcanological processes such as eruption of obsidian flows (e.g., Eichelberger et al., 1986; Fink and Manley, 1987), vesiculation and formation of foams on the contact between hotter mafic and colder silicic magmas (Eichelberger, 1980 ), gravity instability and floating of rhyolite pumices, spacing of rhyolite vesicular domes (Fink, 1980), duration of rhyolite flows (Manley, 1992), ejection of tephra and pumices (Wilson, 1980), etc. This light and poorly conductive geomaterial possessing time-dependent physical properties remains, however, poorly investigated. The present work is a comparative experimental study of thermal properties of rhyolite melt and rhyolite foam with a special emphysis on the role of the foaming process on thermal boundary conditions of magmatic systems.

The importance of thermal boundary conditions on the heat transfer regime of a convective magma chamber has been already pointed out in the volcanological literature (e.g., Carrigan, 1988 ). Precisely which kind of temperature conditions obtain on the contact between magma and host rocks can be analysed using a Biot number $B i$ (Carrigan, 1988), which characterizes the ratio of the thermal resistance of magma to the thermal resistance of host rocks. As $B i \rightarrow \infty$, the high thermal conductivity of the host rocks results in a constant boundary temperature. As $B i \rightarrow 0$, the host rocks thermally insulate the underlying magma and constant heat flux conditions should be applied. In the ideal case of perfect thermal insulation (zero thermal conductivity and infinite thickness of overlying host rocks) this "thermos bottle" effect can effectively suppress the convection in magma chambers, which will never cool or crystallize in 
this situation. In reality, a non-zero heat flux always exists as small as several HFU. It can even be much higher if a hydrothermal convection of fluids develops above the magmatic reservoir.

A sudden drop of pressure, due to the fracturing of the magma carapace (Marsh, 1984) or tectonic unloading of the volcanic edifice caused by a landslide (i.e. Eichelberger and Hayes, 1982), will result in melt vesiculation. At this moment the expansion wave propagates down into magma, allowing its rapid decompression (Heiken and Wohletz, 1991). Thus, behind the front of the wave the foamed layer forms inside a degassing magma chamber in locations where the magma is supersaturated in volatiles (predominantly on the top, i.e. Blake, 1984). The thermal and mechanical properties of this layer are poorly known. This study presents the first experimental determinations of the thermal diffusivity of a rhyolite foam and includes an appraisal of the possibility of a "thermos bottle" effect of natural foam on the evolution of convective patterns in shallow magma chambers. The simple numerical model of magma chamber convection used, is purely for illustrative purposes.

\section{Sample preparation}

Samples of rhyolite melt and rhyolite were generated from a sample of Little Glass Mountain Obsidian, provided by J. Fink, whose rheological properties and composition have been reported previously (Bagdassarov and Dingwell, 1993). Vesiculation of LGM obsidian generates foams with practically uniform size distribution because bubbles nucleate heterogeneously on microlites. The preparation of the rhyolite melt has been described by Webb and Dingwell (1990). Samples of rhyolite foam were obtained from heating small chips of obsidian (3-5 g) for $1-2 \mathrm{~h}$ in $50 \mathrm{~cm} \mathrm{Pt}_{95} \mathrm{Au}_{5}$ crucible at temperatures immediately below the dominant gas release temperature $\left(1050-1200^{\circ} \mathrm{C}\right.$, Fig. 1). This temperature has been determined in gas release profiles of obsidian samples on a thermoanalyzer combined with a quadrupole mass spectrometer (Heide, 1991). The physical meaning of the gas release temperature is the temperature range in which the process of bubble growth is diffusiondominated (Hampton and Bailey, 1984). The viscosity of the rhyolite melt at this temperature range varies from $10^{8} \mathrm{~Pa}$ at $1065^{\circ} \mathrm{C}$ to $10^{6.7} \mathrm{~Pa} \mathrm{~s}$ at $1185^{\circ} \mathrm{C}$ (Webb and Dingwell, 1990). This

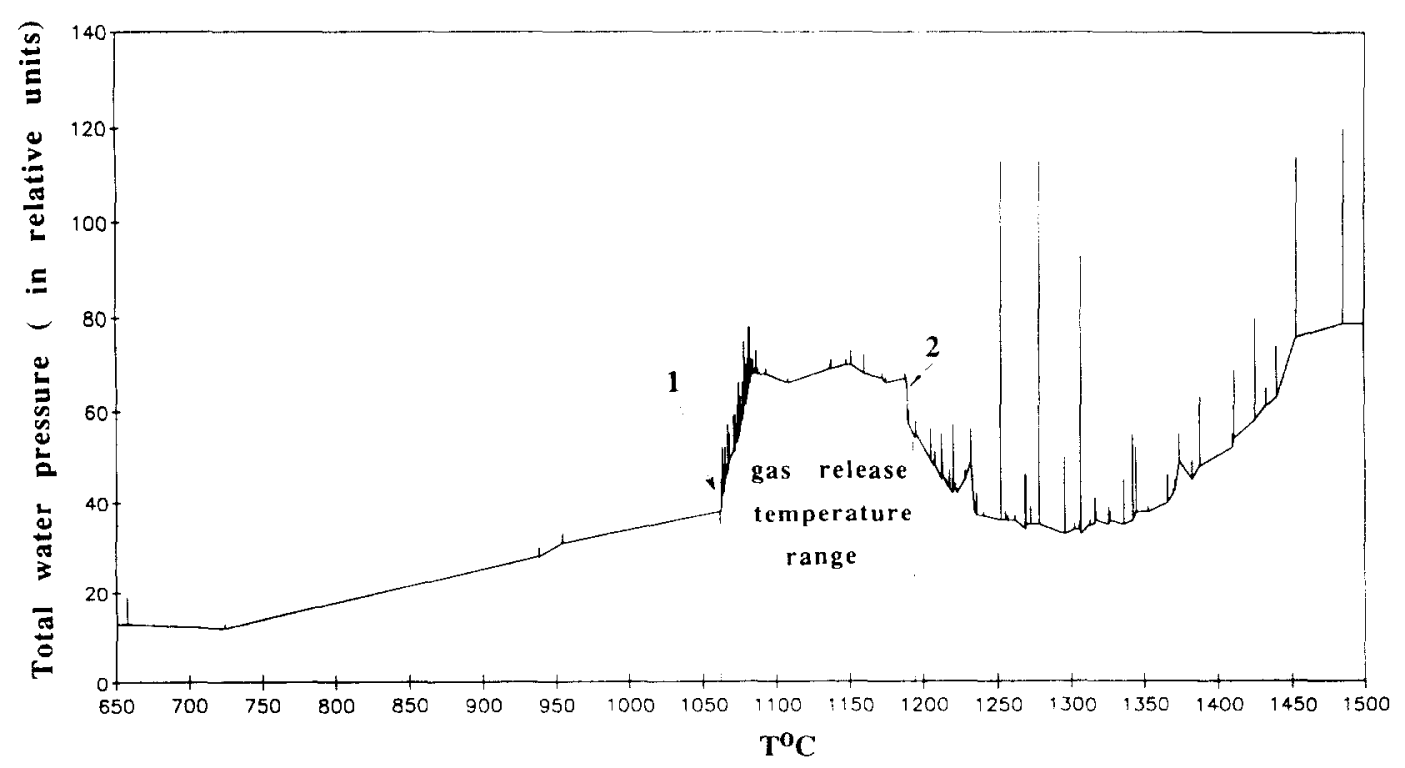

Fig. 1. Gas release profile for Little Glass Mountain obsidian. $I=$ viscosity $10^{8} \mathrm{~Pa}$ s; $2=10^{6.7} \mathrm{~Pa}$ s. 
shape of gas release profile has been noted in many felsic melts (Hampton and Bailey, 1984) and relates to formation and growth of bubbles (Sparks, 1978).

Diffusional growth stabilizes the size distribution of growing bubbles, the rate of growth for big bubbles is less than for smaller ones (Toramaru, 1989). Below and at the gas release temperature the growth process of vesicles is diffusional, the mass flux into bubbles mainly consists of a diffusional flux of water dissolved in the surrounding melt. Due to the high viscosity (low diffusion coefficient ), nucleation does not overlap with the coalescence of bubbles. At higher temperatures the mechanism of bubble growth is expansional (advective mass flux) and it results in coarse and very labile foam formation. At these temperatures the growth rate is high enough, thus, nucleation and coalescence processes occur simultaneously. The advective contribution of mass flux into growing bubbles comes from the fast expansion of the surface of vesicles. Big bubbles grow and consume smaller ones, the rate of their expansion is faster than for small bubbles, and, thus, there is no stabilizing factor on the size distribution of vesicles.

After annealing of obsidian the cylindrical samples ( $\sim 22 \mathrm{~mm}$ in diameter and $\sim 55 \mathrm{~mm}$ in length) were cored from the crucible using diamond tools and the ends were ground flat. The porosity of the obtained rhyolite foam $(\phi)$ was determined using their measured mass, and volume derived from their regular geometry.

\section{Experiments}

The experimental procedure which has been used for measurements of thermal diffusivity is based on a radiative heat flow method (e.g., Sheffield and Vukovich, 1987) appropriate for an intermediate size of sample (few $\mathrm{cm}$ ) with low thermal conductivity and high porosity. Solid cylindrical samples of a rhyolite foam were cut along their axis and three thermocouples (Pt$\mathrm{PtRh}_{10}, 0.25 \mathrm{~mm}$ diameter for glass sample) were laid into the grooves on the cut surface, sandwiched and glued to the other half-cylinder.
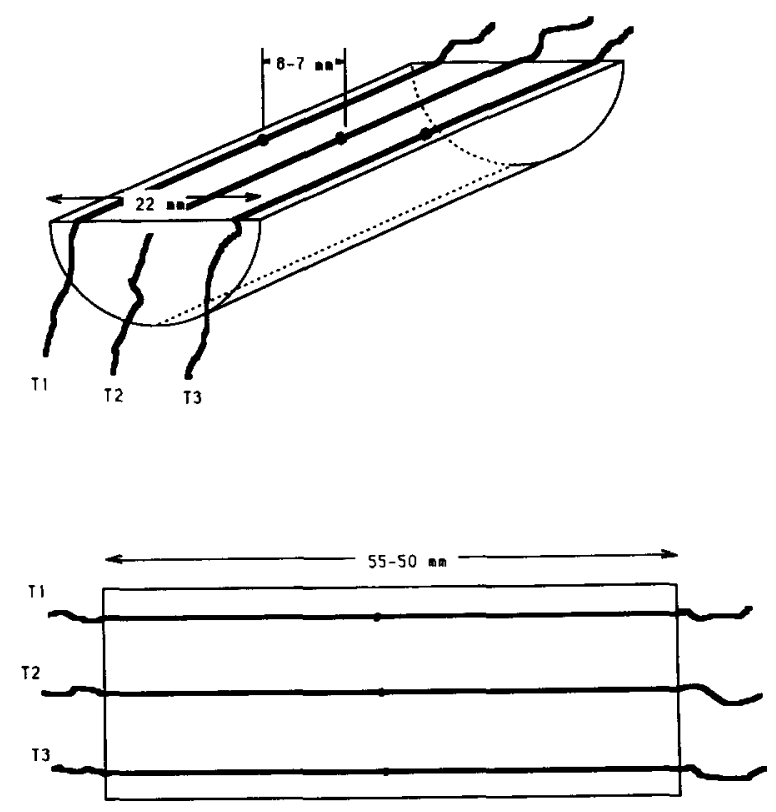

Fig. 2. Principal scheme of measurements.

Sample diameters were $\sim 22 \mathrm{~mm}$, lengths $\sim 55$ $\mathrm{mm}$ (Fig. 2). In the case of rhyolite foams, three alumina tubes (outer diameter $1 \mathrm{~mm}$, inner diameter $0.5 \mathrm{~mm}$ for $\mathrm{Pt}-\mathrm{PtRh}_{10}$ thermocouples 0.1 $\mathrm{mm}$ in diameter) were installed in samples at the stage of foaming of small obsidian chips. One thermocouple was installed along the axis of the sample, and two other thermocouples at a distance of 7-8 mm from the central thermocouple and parallel to it. The entire assemblage of sample with thermocouples was then loaded into a horizontal Pyrox ${ }^{\circledast}$ tube furnace. The temperature in the furnace was scanned in the range 20$1100^{\circ} \mathrm{C}$ at a approximately constant heating rate and constant cooling rate of $1.5-5 \mathrm{~K} / \mathrm{min}$. The temperature data were read and stored using a Keithley-2001 multimeter with a temperature accuracy $0.01^{\circ} \mathrm{C}$ and a time step of 50-100 s. The temperature of the cold junctions of the thermocouples was stabilised by using the zero-ice-point cell. The use of three thermocouples rather than two increased the precision and confidence of thermal radial gradient measurement. The thermal diffusivity has been determined from the equation: 
$\kappa=\frac{R^{2} \frac{\mathrm{d} T}{\mathrm{~d} t}}{4 \Delta T}$

where $R$ is thermocouple spacing, $\mathrm{d} T / \mathrm{d} t$ is the heating or cooling rate, and $\Delta T$ is the radial gradient of temperature. The error in spacing is $\sim 0.75-1 \%$, in radial thermal gradient $\sim 5 \%$, in heating (cooling rate) $\sim 0.5-0.75 \%$. The total probable experimental error is $\sim 7-8 \%$. The difference in measured thermal diffusivity during heating and cooling was $\sim 8-10 \%$ at low temperatures and $12-16 \%$ at high temperatures. Figures 3 and 4 show the results of the thermal diffusivity measurements on rhyolite melt and foam. The data for melt have been obtained on heating (Fig. 3 ), they are less scattered than the data on rhyolite foam (Fig. 4) collected either on heating or on cooling. The precision of the method has been tested on a industrial fire brick with constant thermal diffusivity $\kappa=0.0048 \times 10^{-4}+9 \times 10^{-11}$ $(T-273) \mathrm{m}^{2} / \mathrm{s}$ (Fig. 5). This porous material yields a precision $<15 \%$ (Sheffield and Vukov- ich, 1987) and possesses low thermal conductivity close to the conductivity of foamed samples $\sim 0.62 \mathrm{~W} \mathrm{~m}^{-1} \mathrm{~K}^{-1}$ at $1273 \mathrm{~K}$ (Sheffield and Vukovich, 1987).

The results of the thermal diffusivity measurements are summarized in Fig. 5. At low temperatures the thermal diffusivity of rhyolite foam is lower than for melt by a factor proportional to the volume fraction of melt in the porous rhyolite melt sample. This is consistent with the thermal conductivity theory of porous materials (Loeb, 1954). When pores are closed and small enough to prevent convective heat transfer inside them the total thermal conductivity can drop significantly. This effect is used in production of so called thermal superinsulators (pore diameter $<1 \mu \mathrm{m}$ ) in which the thermal conductivity is in several orders of magnitude less than in solid matrix (Parrot and Stuckes, 1975). In our foamed rhyolite the pore size is about $100-200$ $\mu \mathrm{m}$, thus, the convective heat transfer inside bubbles is excluded, and radiative heat transfer is weak due to multiple reflections on bubble surfaces and to an increase of the optical absorp-

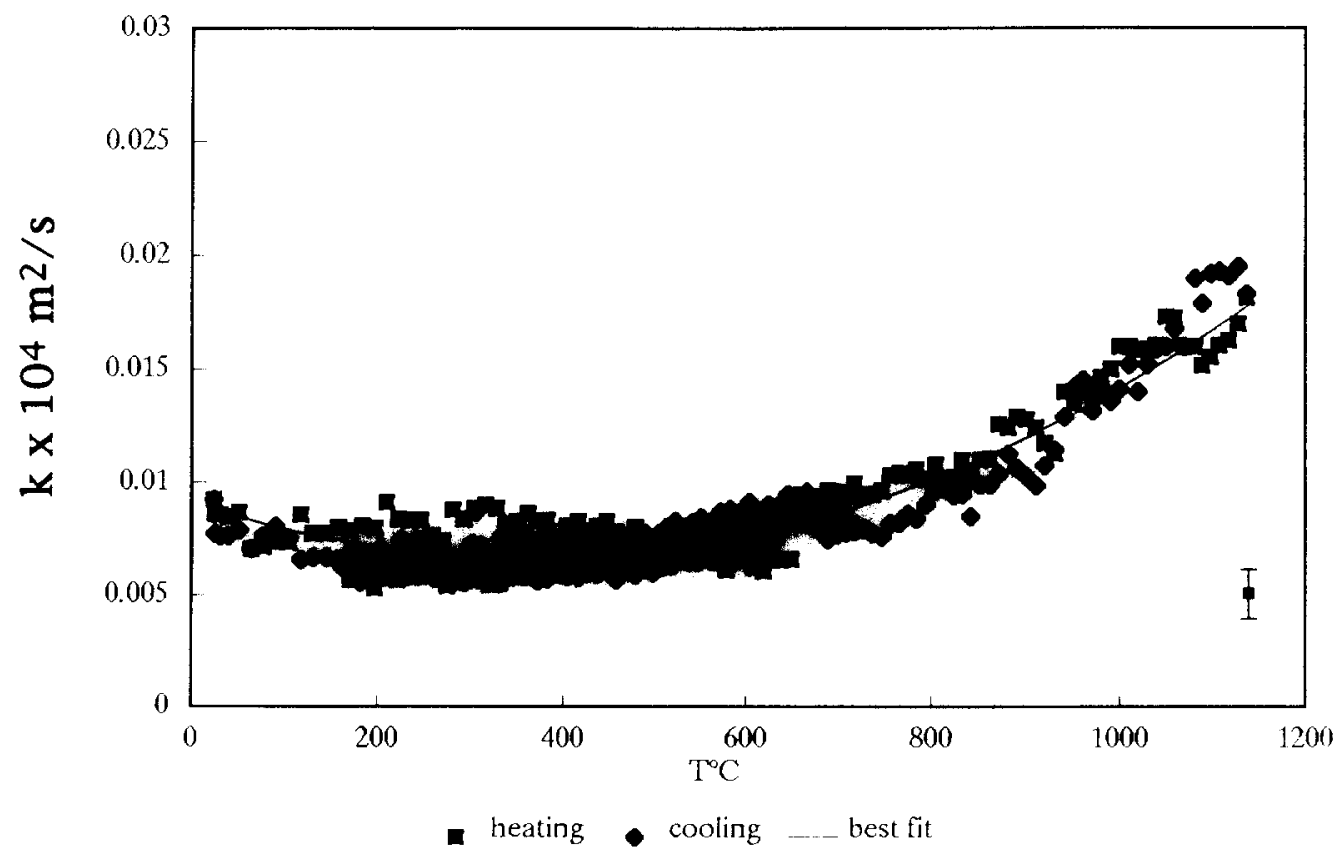

Fig. 3. Thermal diffusivity of LGM rhyolite melt. 


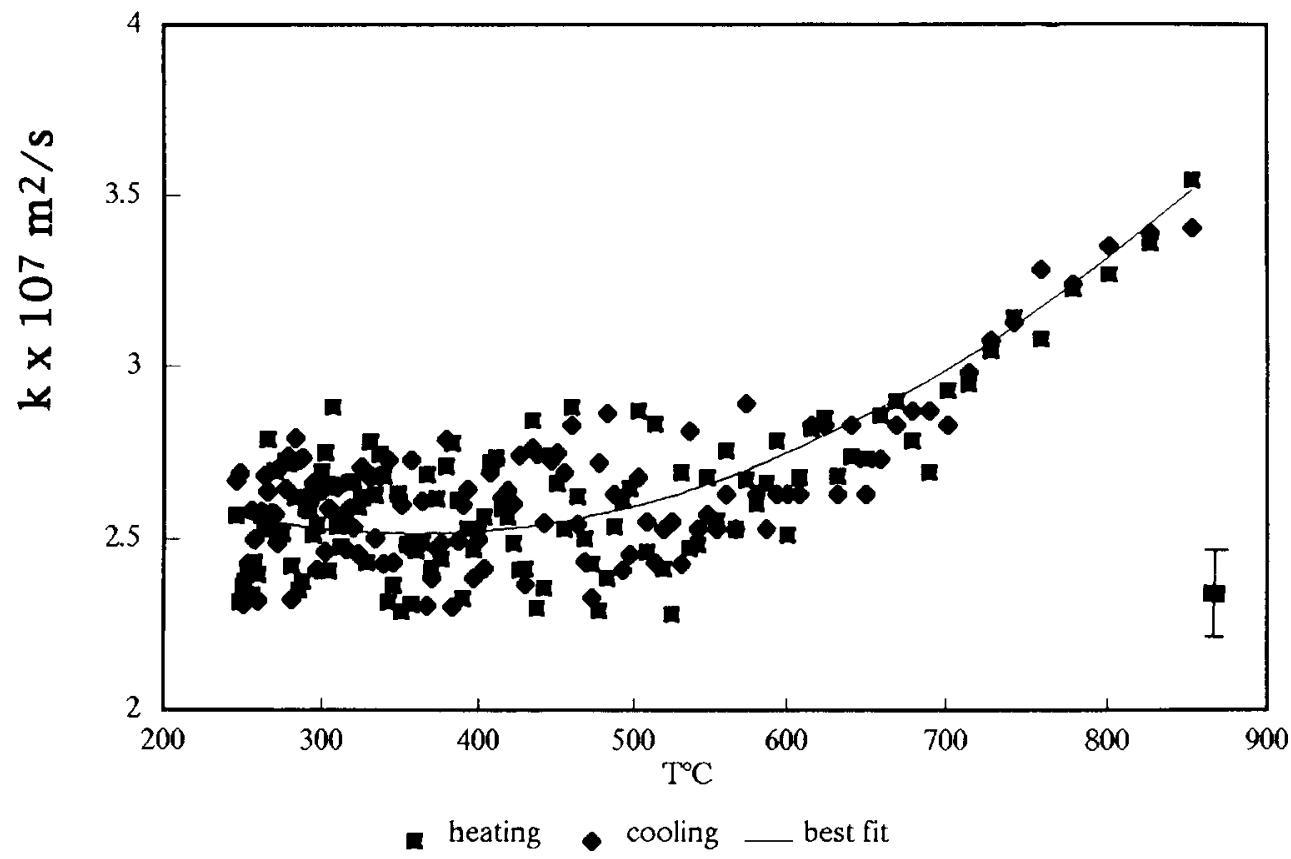

Fig. 4. Thermal diffusivity of LGM obsidian foam (70-80\% porosity).

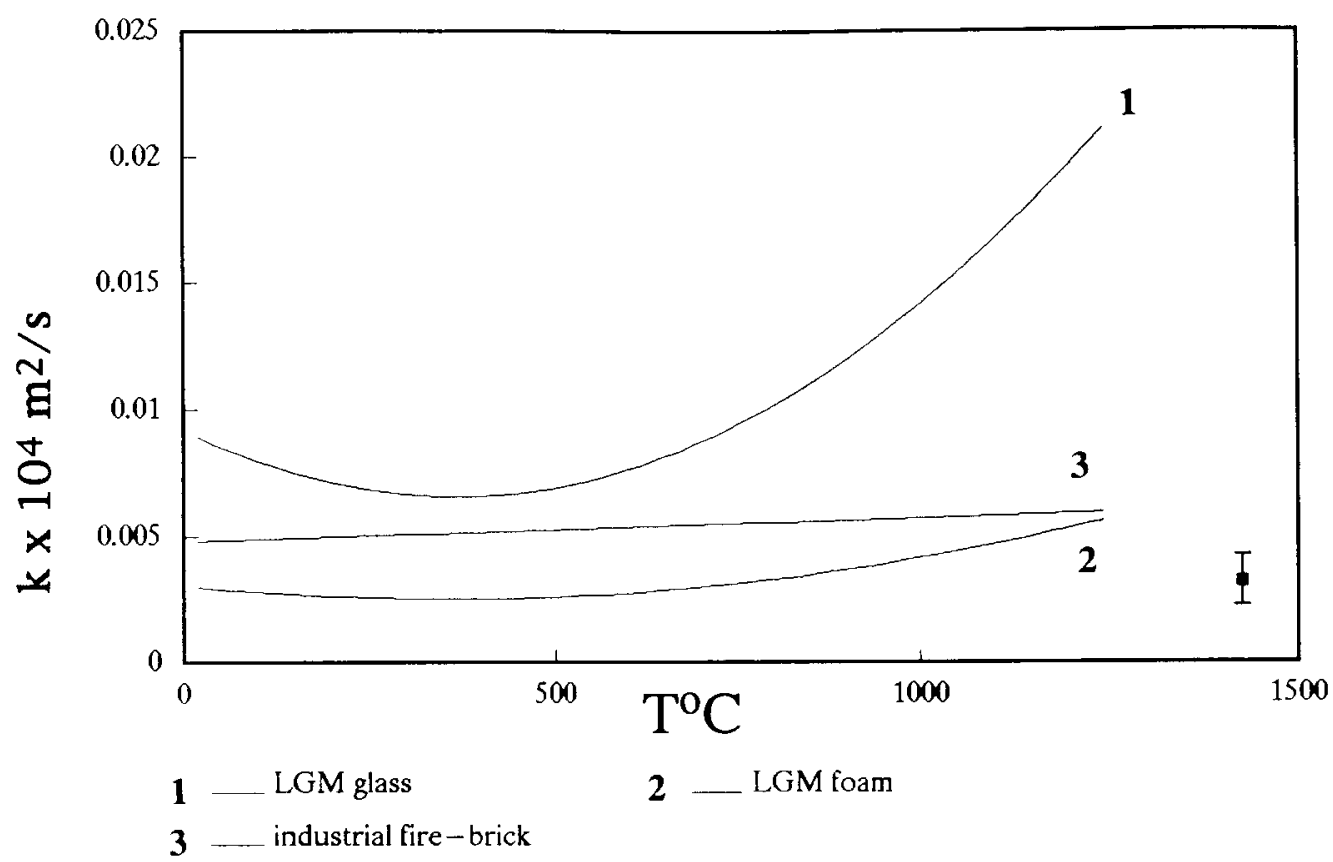

Fig. 5. Thermal diffusivity of rhyolite foam and melt. $1=$ rhyolite melt; $2=$ rhyolite foam $70-80 \%$ porosity; $3=$ industrial fire brick. 
tion due to the effective elongation of the optical path in melt films separating bubbles. The smaller size of bubbles, the more opaque the material is, and the lower the radiative component of thermal conductivity. This fact results in thermal insulating properties of natural foams at high temperatures. Thus, at higher temperatures $\left(>600-650^{\circ} \mathrm{C}\right)$, the observed difference in thermal conductivity between rhyolite melt and foam is more significant, presumably due to the high radiative component of heat transfer in melt (rhyolite melt is transparent, rhyolite foam is more opaque).

The temperature dependence of thermal diffusivity for rhyolite melt and foam of $70-80 \%$ porosity can be described as follows:

$$
\begin{aligned}
& k_{\text {melt }}=0.00914 \times 10^{-4}-1.4 \\
& \quad \times 10^{-9}(\mathrm{~T}-273)+1.9 \times 10^{-12}(\mathrm{~T}-273)^{2} \\
& k_{\text {foam }}=0.00304 \times 10^{-4}-2.9 \\
& \quad \times 10^{-10}(\mathrm{~T}-273)+4 \times 10^{-13}(\mathrm{~T}-273)^{2}
\end{aligned}
$$

where $T=\mathrm{K}, \kappa=\mathrm{m}^{2} / \mathrm{s}$.

The thermal conductivity has been calculated from the thermal diffusivity data by the relationship:

$K=\rho C_{\mathrm{p}} \kappa$

where $\rho$ is density and $C_{\mathrm{p}}$ is the specific heat. The temperature dependence of $C_{\mathrm{p}}$ of rhyolite melt of this composition have been determined recently (Neuville et al., 1993). The temperature dependence of $\rho$ has been derived from the linear thermal expansion coefficient in the range of 30 $900^{\circ} \mathrm{C}$ :

$$
\begin{aligned}
& \rho=\rho_{\mathrm{o}}\left[1+4.635 \times 10^{-6}(T-273)\right. \\
&+\left.0.654 \times 10^{-9}(T-273)^{2}\right]^{-3}
\end{aligned}
$$

measured in this sample (Webb, 1992). The density of rhyolite melt at room temperature $\rho_{\mathrm{o}}=2.33 \times 10^{3} \mathrm{~kg} / \mathrm{m}^{3}$ has been determined from Archimedean buoyancy density measurements. The temperature dependence of density and specific heat of rhyolite foam has been calculated using the same expressions corrected for the volume porosity $\phi$ (e.g., Lee and Taylor, 1978):
$C_{\mathrm{p}}^{\text {foam }} \rho^{\text {foam }}=\phi C_{\mathrm{p}}^{\text {gas }} \rho^{\text {gas }}+(1-\phi) C_{\mathrm{p}}^{\text {melt }} \rho^{\text {melt }}$

The results of thermal conductivity calculations are shown in Fig. 6. The data obtained agree well with the data on obsidian melts at low temperatures (Birch and Clark, 1940; Murase and McBirney, 1973). The measured thermal conductivity of rhyolite melt at room temperature of $3.8 \mathrm{mcal} \mathrm{cm}^{-1} \mathrm{~s}^{-1} \mathrm{~K}^{-1}$ (or $\sim 1.59 \mathrm{~W} \mathrm{~m}^{-1} \mathrm{~K}^{-1}$ ) compares well with the data on the obsidian melt of $3.21 \mathrm{mcal} \mathrm{cm}^{-1} \mathrm{~s}^{-1} \mathrm{~K}^{-1}$ ( or $1.33 \mathrm{~W} \mathrm{~m}^{-1} \mathrm{~K}^{-1}$ ) (Birch and Clark, 1940) and with the value calculated from oxide composition of the rhyolite melt (3.2 mcal cm $\left.\mathrm{cm}^{-1} \mathrm{~s}^{-1} \mathrm{~K}^{-1}\right)$ using the expression:

$K=2.371+\Sigma X_{i} P_{i}$

where $K$ is the thermal conductivity in $\mathrm{W} \mathrm{m}^{-1} \mathrm{~K}^{-1}, X_{i}$ is the mass fraction of oxide component, $P_{i}$ is the partial coefficient for each oxide. The coefficients $P_{i}$ (in $\mathrm{W} \mathrm{m}^{-1} \mathrm{~K}^{-1}$ ) are $P\left(\mathrm{SiO}_{2}\right)=-1.062, \quad P\left(\mathrm{Al}_{2} \mathrm{O}_{3}\right)=+0.449$, $P\left(\mathrm{Na}_{2} \mathrm{O}\right)=-1.952, \quad P\left(\mathrm{~K}_{2} \mathrm{O}\right)=-3.939$, $P(\mathrm{CaO})=-1.905, \quad P(\mathrm{MgO})=-3.318$, $P(\mathrm{FeO})=-1.687$ (Geotti-Bianchini and Lohrengel, 1993).

There are several expressions for calculations of the effective thermal conductivity from the thermal conductivity of matrix and dispersed phase. Taking into account that the thermal conductivity of gas inside bubbles differs from the melt as much as $1: 100$, the contribution of the gas conductivity can be neglected ( $\left.K_{\text {gas }}\right)$ $\left.K_{\text {melt }} \rightarrow 0\right)$. In this case the effective thermal conductivity calculated from the Rayleigh-Maxwell equation:

$K^{\text {foam }}=K^{\text {melt }}(1-\phi) /(1+\phi)$

or from the Bruggeman variable-dispersive equation:

$K^{\text {foam }}=K^{\text {melt }}(1-\phi)^{3 / 2}$

(Lee and Taylor, 1978). From the experiments we get $K_{\text {foam }} / K_{\text {melt }}$ about 0.1 at temperatures $300-$ $1000 \mathrm{~K}$, and the ratio is even lower at temperatures $>1000 \mathrm{~K}$. 


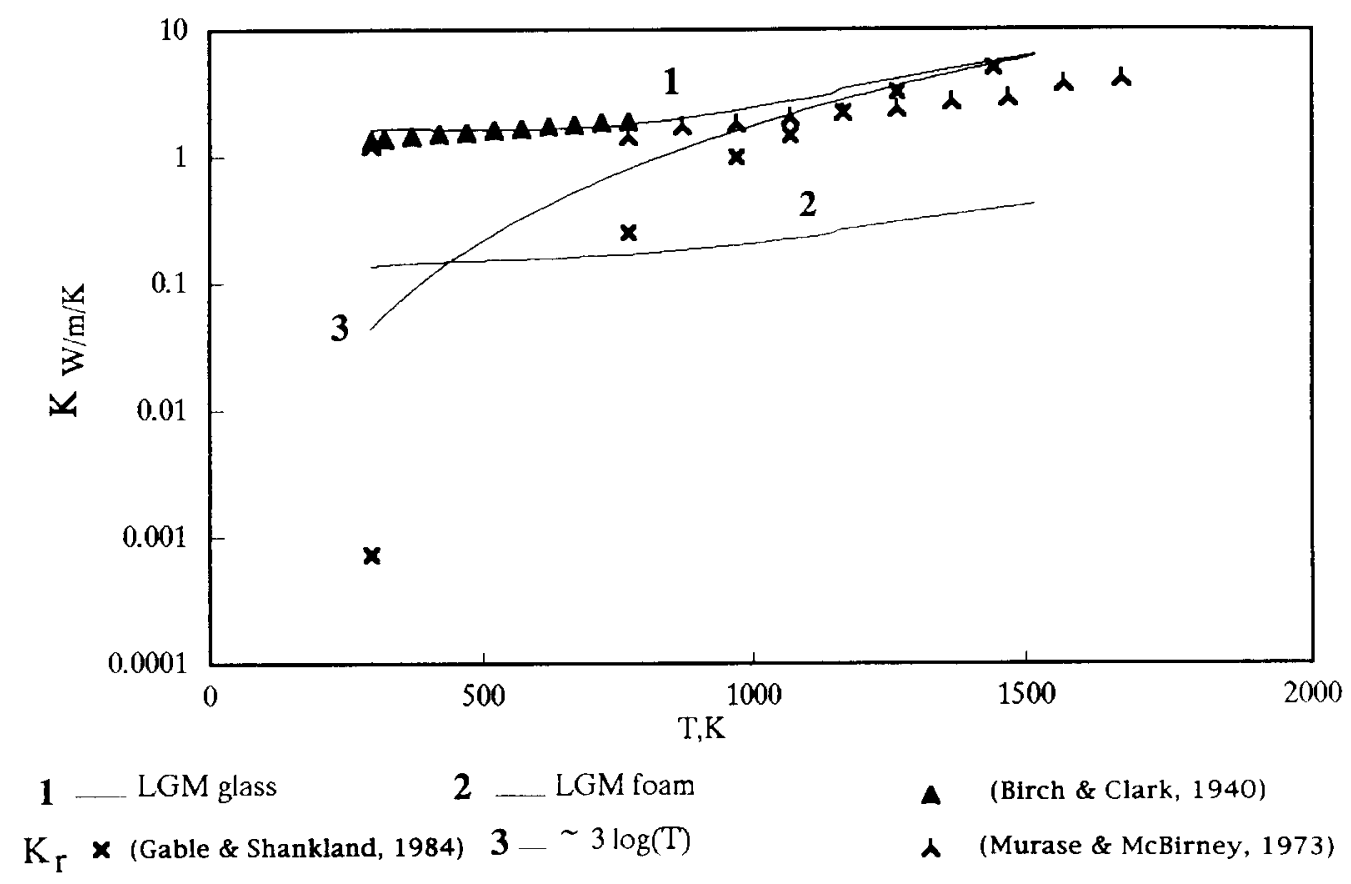

Fig. 6. Thermal conductivity of rhyolite melt and foam. $1=$ rhyolite melt; $2=$ rhyolite foam; $3=$ theoretical dependence of radiative thermal conductivity $\left(\sim T^{3}\right)$; crosses = radiative component of thermal conductivity (Gable and Shankland, 1984); triangles = thermal conductivity of the Modoc obsidian melt (Birch and Clark, 1940); triangular asterics=the Newberry obsidian melt (Murase and McBirney, 1973).

Total thermal conductivity is a sum of lattice and radiative conductivities. Above the melt transition $\left(\sim 855^{\circ} \mathrm{C}\right)$ the thermal conductivity increases because the radiative component is growing as $\sim T^{3}$. The only available data on the radiative thermal conductivity of rhyolite melt are those of Gable and Shankland (1984) which agree well with the data obtained in this study and disagree with data on the Newberry obsidian melt (Murase and McBirney, 1973). At temperatures relatively close to the obsidian vesiculation and petrogenesis of rhyolite foam, the ratio of thermal conductivities of melt and foam increases to as high as a factor of $\sim 10$.

\section{Convection in a magma chamber with foamed layer on the top}

The effect of the formation of a foamed layer on top of a convecting magma chamber is illustrated using a simple numerical model of magma chamber convection. The model is oversimplified and does not take into account crystallization of magma near the chamber roof. The thermal and buoyancy effects of crystallization will certainly influence the style of magma chamber convection (i.e. Brandeis and Marsh, 1989; Worster et al., 1993), but they are beyond the scope of the present paper. For purely illustrative purposes, the magma chamber is regarded as a horizontal liquid layer and, in the analysis of the thermal convective instability, the classical thermal Rayleigh number $(R a)$ is based on the depth of the liquid layer. In reality, if the effects of latent heat and viscosity of mushy zones are taken into account, the convective motion may be weak, even if the calculated Rayleigh number $R a$ is higher than the critical one (Oldenburg and Spera, 1991). They have demonstrated by numerical simulation that in a vertical convective cell, with the crystallizing liquid having a binary eutectic phase diagram, the solidification decreases convective vigour by reducing the heat 
flux in a solid and increasing the effective viscosity in a mushy zone.

Usually, the problem of determining conditions of the onset of convection in a magma chamber is concentrated on the case where boundaries are of infinite conductivity (i.e. a constant boundary temperature ) or at a constant heat flux. In the case of non-slip boundaries with fixed temperature the critical Rayleigh number $(R a)$ for convective onset in a horizontal liquid layer is $\sim 1708$ (Jeffreys, 1926). The finite thermal conductivity of the surrounding rock changes the conditions for the onset of convection. Depending on the ratio, the thermal conductivities of convecting melt and overlying host rocks and their relative thickness, the critical Rayleigh number $(R a)$ and critical wavelength $(a)$ number decrease (e.g., Hurle et al., 1967; Nield, 1968 ). For example, in the case when a liquid layer is enclosed between a perfect thermal insulator (upper boundary) and a lower boundary with the fixed temperature (perfect thermal conductor , a critical $R a$ drops to $\sim 1296$ and a critical wavelength number $a=2.55$ (Nield, 1968). As the relative thermal conductivity of host rocks decreases, the length of a critical disturbance in the convective cell increases. The critical motion becomes practically horizontal; thus, after the thermal insulation of horizontal boundaries the vertical motion and vertical convective heat flux in a cell is no longer efficient.

Additionally, if the thermal insulator is put on top of the convective layer, the temperature of the upper boundary increases and the driving temperature difference in the convective cell decreases (thermos bottle effect). Consider that a foamed layer with thickness $\delta$ and thermal conductivity $K^{\prime}$ is placed on top of a convecting layer with thickness $d$ and thermal conductivity $K$ (Fig. 7 ). Assume that the outer plane of layer $\delta$ and lower plane of layer $d$ are held at uniform temperatures 0 and $T_{\mathrm{o}}$ respectively. The steady temperature $(t \rightarrow \infty)$ on the boundary between them (or on the upper boundary of layer $d$ ) is given by:

$$
T=\frac{T_{\mathrm{o}}}{1+\frac{K \delta}{K^{\prime} d}}=\frac{T_{\mathrm{o}}}{1+\beta}
$$

where $\beta$ is a dimensionless parameter characterizing the efficiency of thermal insulation (Nield, 1968). The better the thermal insulation of the convecting layer $d$, the closer is the temperature difference between two boundaries of the convective layer to zero. Thus, when the thermal insulation is efficient at some moment, the convection in the layer is suppressed and the heat transport through the system is purely conductive (Nusselt number $N u \rightarrow 1$ ). If the decrease in heat flux due to the thermal insulation of the upper boundary is not enough to suppress the convection, its efficiency reduces proportionally to the cubic root of the heat flux decrease $N u$ $\sim R a^{1 / 3}$ (e.g., Turner, 1973). As this study shows, the ratio of the thermal conductivity of rhyolite melt to foam $\left(K / K^{\prime}\right)$ can be as much as $10-12$. Assuming that the relative thickness of the foamed layer on the top $(\delta / d)$ can be of the order of 1-2 the maximum realistic value of parameter $\beta=(K \delta) /\left(K^{\prime} d\right) \sim 0.05$.

The situation has been numerically simulated for the 2-D case of convection in a square box. The mathematical formulation of the problem and numerical procedure of the solving the system for the convective equations has been discussed earlier (Bagdassarov and Fradkov, 1993). In Fig. 8 the temperature evolution patterns of decaying convection are shown. The layer of thermal insulator with $\beta=0.05$ has been placed on the top of a cell with the developed convection with Rayleigh number $R a=10^{4}$ (Fig. 8a). Starting from the developed convection pattern $(N u \sim 4.65)$ the convective motion decays with time to a pure conductive regime of heat transfer through the cell (Fig. $8 \mathrm{e}$ ) with $N u=1$. When the insulating parameter $\beta$ is not sufficiently small, the convective motion below the thermally insulating boundary will continue, because now the temperature difference between the upper and the lower boundaries decreases but not as much to suppress the convection (Fig. 9b). The $\beta$ value of 0.05 is sufficient to suppress convection with $R a=10^{4}$ but is too large to suppress convection with higher Rayleigh numbers. The complete decay of convective patterns in a cell with starting 


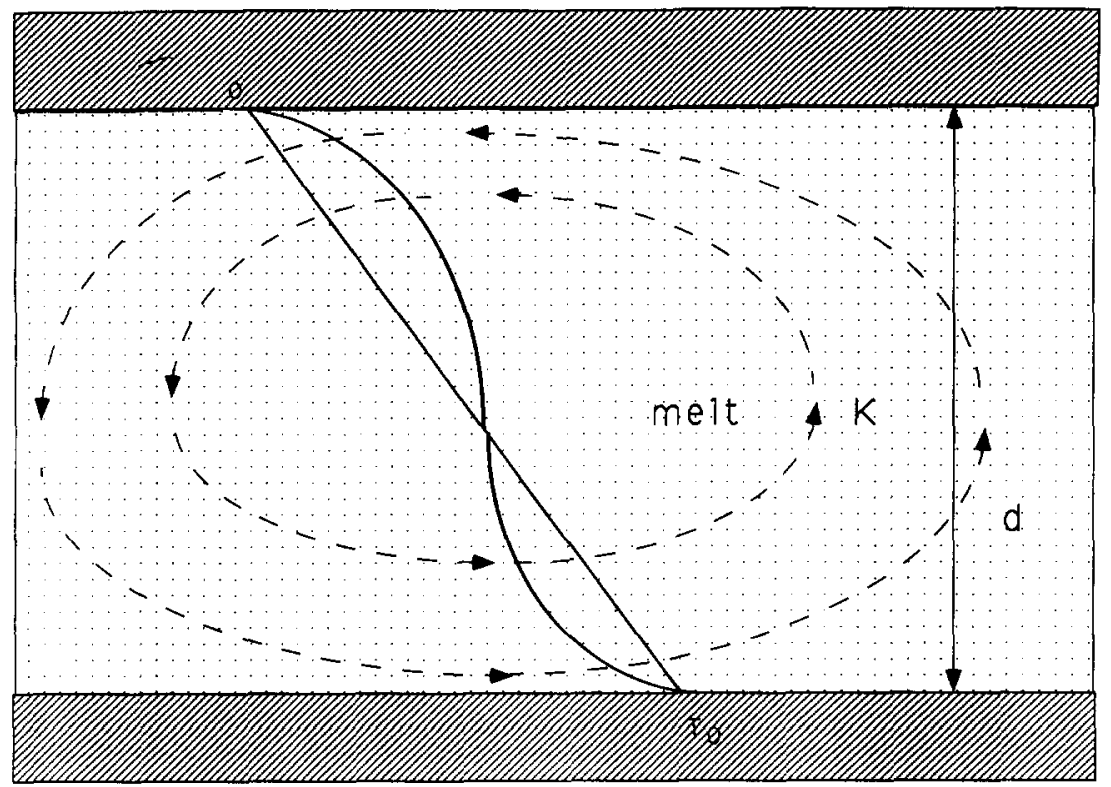

a

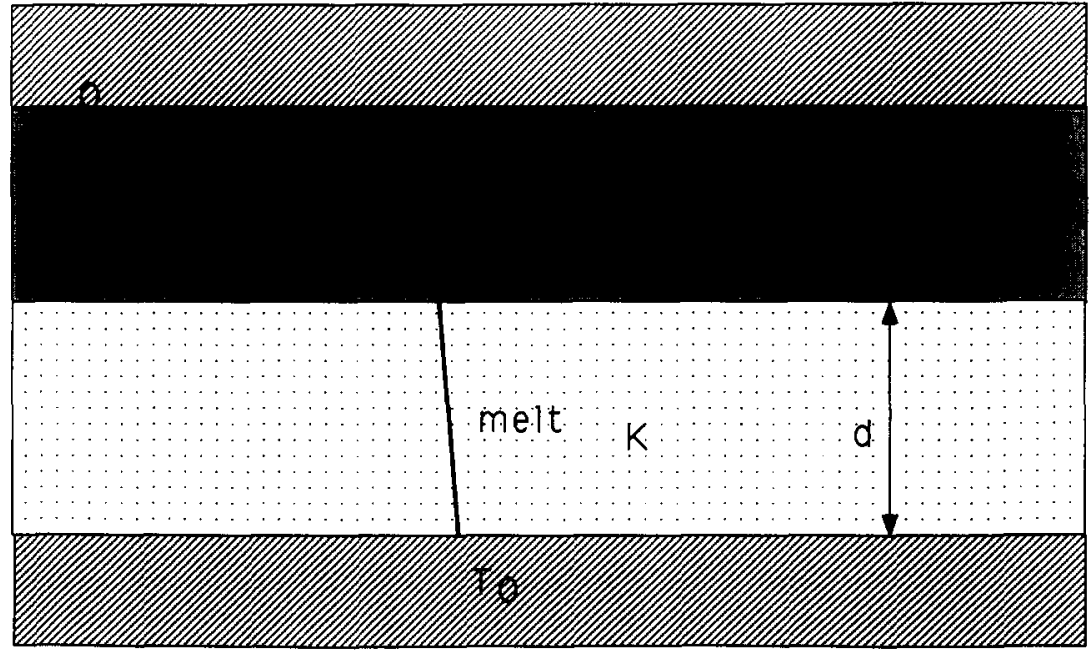

b

Fig. 7. Principle of "thermos effect" on suppressing convection in magma chamber. (a) Steady-state convection and temperature profile without foamed layer on the top. (b) Temperature profile after formation the foamed layer.

$R a=10^{5}$ occurs when parameter $\beta=0.005$. The calculated Rayleigh number for most magma chambers is usually much higher than $10^{4}-10^{5}$. It means that the "thermos effect" of a foam layer near the roof can only reduce the effective Rayleigh number of a convective cell by not more than a factor of 100 . Convection in the magma chamber may be suppressed entirely by the foaming cap effect only when $R a<10^{5}$. The situation described above is related mostly to magma chambers in the shape of thin sills where the heat losses through the sidewalls are much 

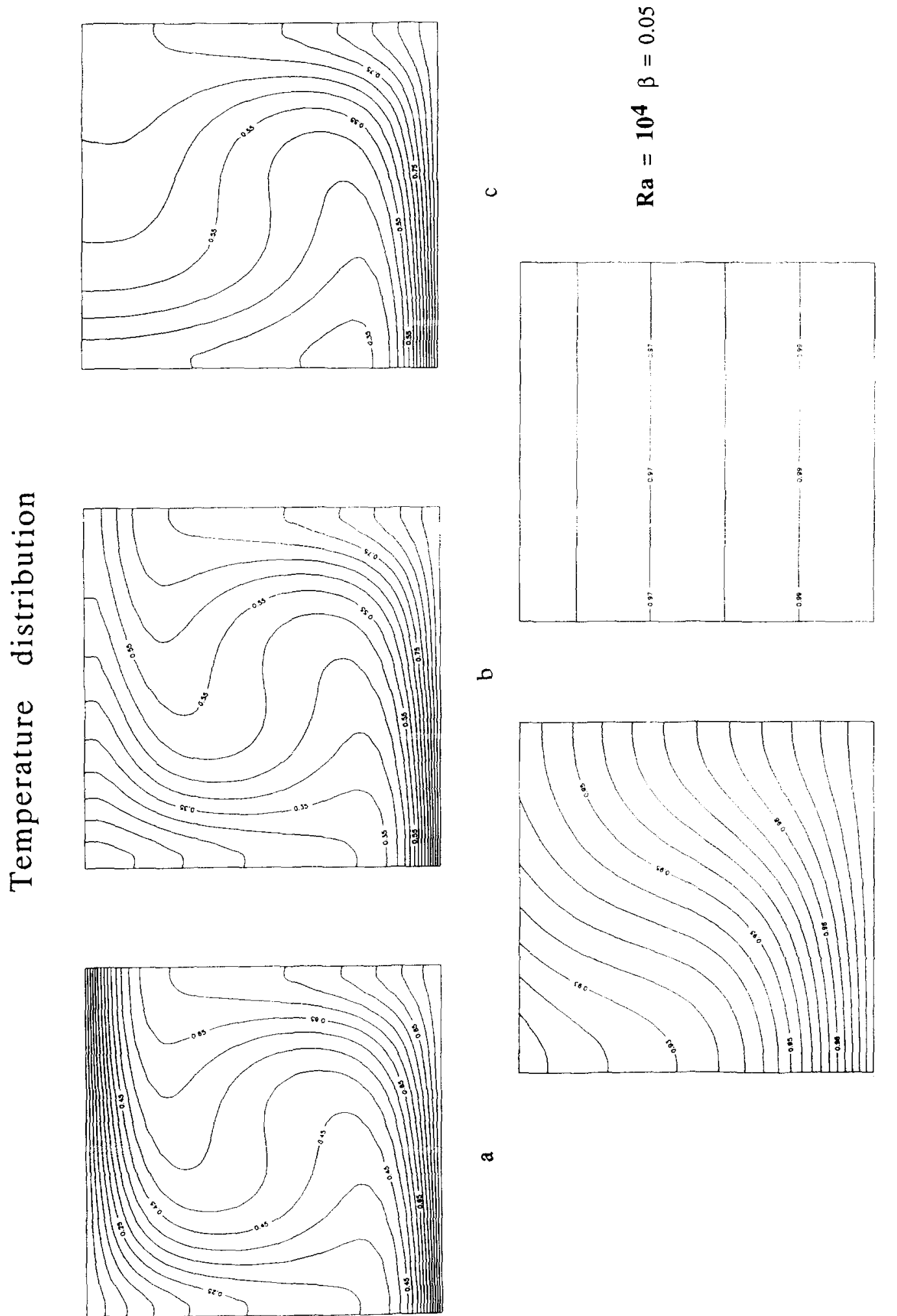

$\varpi$ 

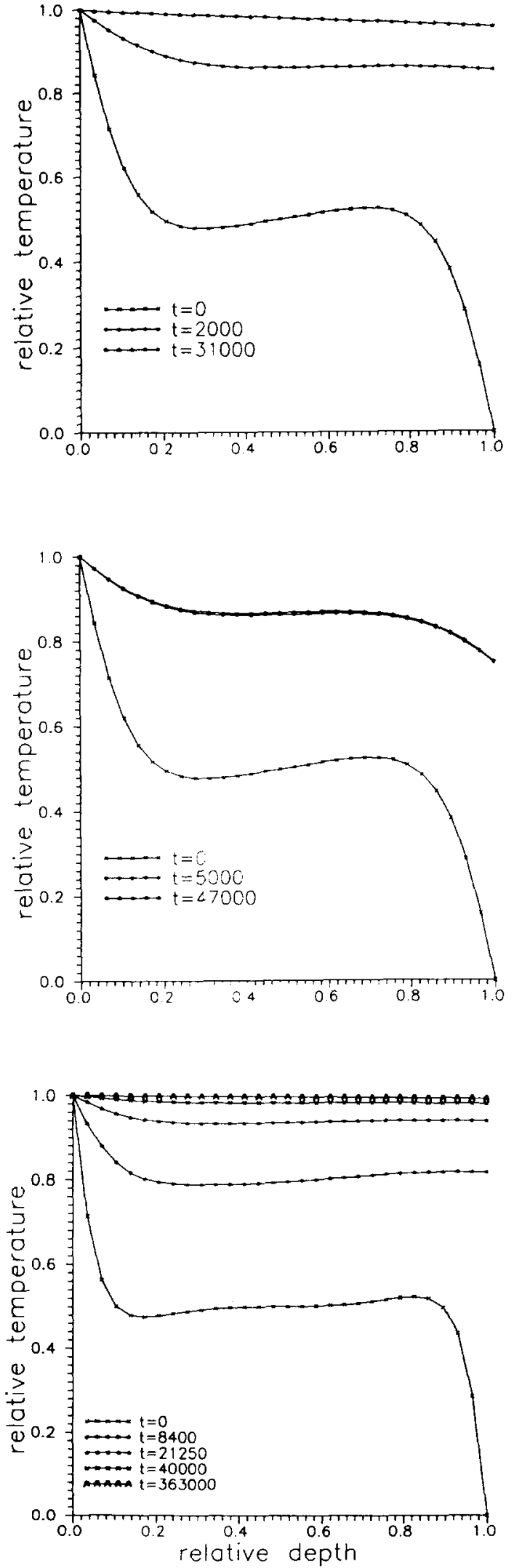

lower than through the roof. When the sidewall heat losses are significant, only an "ideal" thermal insulation by foaming near chamber walls can suppress the magma convection.

\section{Discussion}

Scenarios which can result in the formation of a foamed layer on the top of shallow magma chamber have been simulated in laboratory conditions and discussed in the volcanological literature (e.g., Jaupart and Vergniolle, 1989). The mechanical resistance of a foam layer to collapse influences the time-scale of at least two processes. The first is thermal insulation of underlying melt and the decay of convection within it. The second is the bursting of large gas pockets which may be responsible for Strombolian type eruptions (Wilson, 1980). Depending on two dimensionless numbers (Jaupart and Vergniolle, 1989) the steady-state flow or collapse of foam may be observed in an open volcanic system. The possible "shock" of vesiculation resulting from rapid cooling of wet magma injected in a reservoir with cooler silicic magma has been discussed by Eichelberger (1980). Floating of such a layer of lighter material due to RayleighTaylor instability has been suggested as driving force for the large-scale convection in magma reservoirs. The open question is: "What will happen with the heat exchange between two magmas when the foamed layer formed on the interface between?" From the present study, based on experimental determination of the thermal diffusivity of rhyolite foam, the thermal insulating effect of foam on the a convecting magma chamber has been estimated. In contrast, convection in magma chambers of basaltic composition is assumed to be well developed and Rayleigh numbers are relatively high $\left(R a \gg 10^{6}\right)$. The discussed "thermos bottle" effect may still decrease the efficiency of convection proportionally to the cubic root of the heat flux reduction from the top. In silicic magma chambers with high viscosity and $\sim 100 \mathrm{~m}$ height $\left(R a \sim 10^{4}\right.$ $10^{5}$ ), the "thermos bottle" effect may play a sig-

Fig. 9. Evolution of the mean temperature profile through the convective cell as a function of relative time. (a) initial $R a=10^{4}$, thermal insulating parameter $\beta=0.05$; (b) $R a=10^{4}$, $\beta=1$; (c) $R a=10^{5}, \beta=0.005$. 
nificant role in the onset of convection and the thermal regime of volcanic system.

\section{Summary}

(1) The present data for thermal conductivity indicate that rhyolite foam can be ten times as insulating as rhyolite melt at magmatic temperatures.

(2) The "thermos bottle" effect of a foamed layer near the roof of magma chamber can reduce the effective Rayleigh number of convecting cell by a factor of $<10^{2}$. The convection in silicic magma chambers with $R a<10^{5}$ may be suppressed by this effect.

\section{Acknowledgement}

This work was supported by the Alexander von Humboldt Foundation, the Deutsche Forschungsgemeinschaft (Di-431/3-1) and the Council of Europe (EV5V-CT92-0178). Sincere thanks are also due to Prof. K. Heide (Jena) for thermoanalysis of samples, Prof. V. Trubitzyn (Moscow) for the discussion of "thermos bottle" effect, Dr. A. Fradkov (Bonn) for the software, H. Schulze (Bayreuth) for technical help. The helpful comments and additional references of Prof. F. Spera (Santa Barbara), Dr. G. Bergantz (Seattle) and Prof. B. Marsh (Baltimore) have significantly improved the manuscript.

\section{References}

Bagdassarov, N.S. and Dingwell, D.B., 1993. Deformation of vesicular rhyolite under external and internal stresses. Bull. Volcanol., 55: 147-154.

Bagdassarov, N.S. and Fradkov, A.S., 1993. Evolution of double diffusion convection in a felsic magma chamber. J. Volcanol. Geotherm. Res., 54: 291-308.

Birch, F. and Clark, H., 1940. The thermal conductivity of rocks and its dependence upon temperature and composition. Am. J. Sci., 238: 529-558.

Blake, S., 1984. Volatile oversaturation during the evolution of silicic magma chambers as as eruption mechanism. J. Geophys. Res., 89: 8237-8244.

Brandeis, G. and Marsh, B., 1989. The convective liquidus in a solidifying magma chamber: a fluid dynamic investigation. Nature, 339: 613-616.

Carrigan, C.R., 1988. Biot number and thermos bottle effect: implication for magma-chamber convection. Geology, 16: $771-774$.

Eichelberger, J.C., 1980. Vesiculation of mafic magma during replenishment of silicic magma reservoirs. Nature, 288: 446-450.

Eichelberger, J.C. and Hayes, D.B., 1982. Magmatic model for the Mount St. Helens blast of May 18, 1980. J. Geophys. Res., 87: 7727-7738.

Eichelberger, J.C., Carrigan, H.R., Westrich, H.R. and Price, R.H., 1986. Non-explosive silicic volcanism. Nature, 323: 598-602.

Fink, J.H., 1980. Gravity in stability in the holocene Big and Little Melt Mountain rhyolite obsidian flows, Nothern California. Tectonophysics, 66: 147-166.

Fink, J.H., Manley, C.R., 1987. Pumiceous and melty textures in rhyolite flows and implications for eruptions and emplacement. In: J.H. Fink (Editor), The Emplacement of Silicic Domes and Flows. Spec. Pap., Geol. Soc. Am., 212: 77-88.

Gable, C.W. and Shankland, T.J., 1984. Radiative heat transfer in molten and glassy obsidian. J. Geophys. Res., 89: 7107-7110.

Geotti-Bianchini, F. and Lohrengel, J., 1993. Thermal conductivity of float glass at room temperature. Glastech. Ber., 66: 25-29.

Hampton, C.M. and Bailey, D.K., 1984. Gas extraction experiments on volcanic glasses. J. Non-Cryst. Sol., 67: 147168.

Heide, K., 1991. The degassing behavior of natural glasses and implications for their origin. J. Thermal Anal., 37: 1593-1603.

Heiken, G. and Wohletz, K., 1991. Fragmentation processes in explosive volcanic eruptions. In: Sedimentation in Volcanic Settings. SEPM Spec. Publ., 45: 19-26.

Hurle, D.J.J., Jakeman, E. and Pike, E.R., 1967. On the solution of the Benard problem with boundaries of finite conductivity. Proc. R. Soc., Ser. A, 296: 469-475.

Jaupart, C. and Vergniolle, S., 1989. The generation and collapse of foam layer at the roof of a basaltic magma chamber. J. Fluid Mech., 203: 347-380.

Jeffreys, H., 1926. The stability of a layer heated from below. Philos. Mag., 2: 833-844.

Lee, T.Y.R. and Taylor, R.E., 1978. Thermal diffusivity of dispersed materials. Trans ASME J. Heat Trans., 100: 720-724.

Loeb, A., 1954. Theory of thermal conductivity of porous materials. J. Am. Ceram. Soc., 37: 96-99.

Manley, C.R., 1992. Extended cooling and viscous flow of large, hot rhyolite lavas: implications of numerical modeling results. J. Volcanol. Geotherm. Res., 53: 27-46.

Marsh, B., 1984. On the mechanics of caldera resurgence. J. Geophys. Res., 89: 8245-8251.

Murase, T. and McBirney, A.R., 1973. Properties of some common igneous rocks and their melts at high tempera- 
tures. Geol. Soc. Am. Bull. 84: 3563-3592.

Neuville, D.R., Courtial, P., Dingwell, D.B. and Richet, P., 1993. Thermodynamic and rheological properties of rhyolite and andesite melts. Contrib. Mineral. Petrol., 113: 572-581.

Nield, D.A., 1968. The Rayleigh-Jeffreys problem with boundary slab of finite conductivity. J. Fluid Mech., 32: 393-398.

Oldenburg, C.M. and Spera, F.J., 1991. Numerical modeling of solidification and convection in a viscous pure binary eutectic system. Int. J. Heat Mass Transfer., 34: 21072121.

Parrot, J.E. and Stuckes, A.D., 1975. Thermal conductivities of solids. Pion Limited, London, pp. 133-134.

Sheffield, G.S. and Vukovich, M., 1987. Operational features and results of a computerized, radial heat flow instrument for determining thermal diffusivity and conductivity. Ceram. Eng. Sci. Proc., 8(1-2): 93-105.

Sparks, R.S.J., 1978. The dynamics of bubble formation and growth in magmas: a revier and analysis. J. Volcanol. Geotherm. Res., 3: 1-37.

Toramaru, A., 1989. Vesiculation process and size distribution in ascending magmas with constant velocities. $J$. Geophys. Res., 94: 17,523-17,542.

Turner, J.S., 1973. Buoyancy Effects in Fluids. Cambridge Univ. Press. Cambridge, 368 pp.

Webb, S.L., 1992. Low-strain frequency shear and structural relaxation in rhyolite melt. Phys. Chem. Minerals, 19: 240245.

Webb, S.L. and Dingwell, D.B., 1990. Non-Newtonian theology of igneous melts at high stresses and strain rates: experimental results for rhyolite, andesite, basalt, and nephelinite. J. Geophys. Res., 95: 15,695-15,701.

Wilson, L., 1980. Relationship between pressure, volatile content and ejecta velocity in three types of volcanic eruptions. J. Volcanol. Geotherm. Res., 8: 297-313.

Worster, M.G., Huppert, H.E. and Sparks, R.S.J., 1993. The crystallization of lava lakes. J. Geophys. Res., 98: 15,89115,901 